\title{
Beta Lactamase Screening Method
}

National Cancer Institute

\section{Source}

National Cancer Institute. Beta Lactamase Screening Method. NCI Thesaurus. Code C85576.

A test that detects beta lactamase produced by Staphylococcus species, Haemophilus species, Moraxella catarrhalis, and Neisseria gonorrhoeae. 